\title{
USE OF MULTI-ANNUAL MODIS LAND SURFACE TEMPERATURE DATA FOR THE CHARACTERIZATION OF THE HEAT REQUIREMENTS FOR GRAPEVINE VARIETIES
}

\author{
Roberto Zorer $^{(1)}$, Duccio Rocchini ${ }^{(1)}$, Luca Delucchi ${ }^{(1)}$, Fabio Zottele ${ }^{(2)}$ Franco Meggio $^{(3)}$, and Markus \\ Neteler $^{(1)}$ \\ (1) GIS and Remote Sensing Unit, Biodiversity and Molecular Ecology Department \\ IASMA Research and Innovation Centre, Fondazione Edmund Mach, Italy \\ ${ }^{(2)}$ Unità Sistema Informativo Geografico SIG \\ IASMA Consulting and Services, Fondazione Edmund Mach, Italy \\ (3) Department of Environmental Agronomy and Crop Science, University of Padova, Italy
}

\begin{abstract}
Heat requirements for grapevine varieties have been widely used to characterize potential growing regions for viticulture. One of the most important indices is the Winkler Index (WI) defined as the total summation of daily average air temperature above $10{ }^{\circ} \mathrm{C}$ from $1^{\text {st }}$ of April to $31^{\text {th }}$ of October in the Northern hemisphere [1]. Mapping of the WI is commonly based on temperature data from meteorological stations. However, in complex terrain such as the European Alps, these are usually irregularly and sparsely distributed or unavailable. This renders traditional geospatial interpolation approaches difficult to become reliable. As an alternative, thermal remote sensing data, which are intrinsically spatialised, can be used. The aim of this work was to provide time series of Winkler Index maps from 2003 to 2010, by means of the MODIS Land Surface Temperature (LST) data and to validate the maps using ground truth data, collected by two weather station networks.
\end{abstract}

Index Terms - Heat requirements, grapevine varieties, MODIS LST, Winkler Index, microclimate.

\section{INTRODUCTION}

Bioclimatic indices have been widely used for mapping the potential distribution of plant species, for the evaluation of agricultural land suitability, to characterize phenological phases [3], for pollen season forecast [6].

Most of the indices are derived from air temperature, precipitation and solar irradiance data and they are mostly calculated as the sum over a specific time interval, which corresponds to the vegetative period, depending also on latitude.

Air temperature-derived indices present often a threshold value, which represents the minimum value, above which temperature condition are favorable for shoot development and plant growth. For grapevines (Vitis vinifera L.), base temperature has been widely accepted at $10^{\circ} \mathrm{C}$ [4]. The best base temperature for the estimation of growing degree hours (GDH) for apple (Malus pumila Miller) was found at $4.4^{\circ} \mathrm{C}[12]$.

Maps of bioclimatic indices are commonly generated by spatial interpolation of data collected from weather stations. However, in complex terrain such as the Central European Alps, meteorological stations are usually irregularly and sparsely distributed or unavailable for cost or other reasons.

This renders traditional geospatial interpolation approaches difficult to become reliable. As an alternative, thermal remote sensing data which are intrinsically spatialized can be used [7].

Such data are available at a global scale (with the problem of cloud contamination). A duty before using these thermal data is proper pre- and postprocessing in order to minimize artifacts in the resulting maps. A polar-orbiting sensor which produces daily Land Surface Temperature (LST) maps with global coverage is MODIS (Moderateresolution Imaging Spectroradiometer) which is flown on the Terra and Aqua satellites [5]. In 2000, the MODIS instrument was launched as a payload on Terra, and in 2002 a second MODIS instrument was launched on Aqua. The MODIS sensor is currently the optimal match between temporal and spatial resolution and is an excellent data source for both local and global change [11]. The processed data are usually published less than one week after acquisition on a NASA FTP site (ftp://e4ft101u.ecs.nasa.gov/).

Clouds and other atmospheric disturbances which may obscure parts of or even the entire satellite image, constitute a significant problem. Despite a series of algorithms applied by NASA to filter clouds in the LST product, outliers still remain (undetected clouds which introduce very low temperatures in the LST maps and reprojection artefacts). Due to this a data reconstruction has to be performed in order to obtain a complete time series. The huge amount of data (to date more than 13,500 MODIS LST maps have 
been collected for each MODIS map tile) requires the automation of the data processing.

From daily time series, for example accumulate growing degree days can be derived [7]. The latter indicator is an important index in agriculture which is used to predict crop maturing or insect development [8] [2].

\section{AIM}

The purpose of this paper is to calculate cumulative growing degree days maps (Winkler Index) derived from aggregated daily MODIS LST, to validate them by ground truth data from weather stations, and finally to assess the suitability for viticulture of the region based on WI classes.

\section{STUDY AREA}

The study area is situated in the central-eastern Alps in Northern Italy. It includes the provinces of Bolzano, Trento and Belluno, as well as parts of the regions of FriuliVenezia Giulia, Lombardy and Veneto.

The study area is showing a south-eastern drainage pattern. It is divided by several dominant wide river valleys with the territory of the provinces of Bolzano and Trento being bisected from north to south by the Adige river valley. It is a predominantly mountainous region encompassing a large part of the Dolomites and the Southern Alps as well as a small parts of the Po river plain. The climate is temperateoceanic with four main areas: sub-Mediterranean (close to Lake Garda, which has mild winters), sub-continental (the main valleys, which have harsher winters), continental (the alpine valleys) and alpine (the areas above the tree line).

\section{MODEL DEVELOPMENT}

MODIS-Terra data are available from 3/2000 onwards, MODIS-Aqua data from 8/2002 onwards. We used the gridded MODIS Land Surface Temperature and Emissivity product (LST/E; MOD11A1 from Terra satellite and MYD11A1 from Aqua satellite) which is provided in equalarea Sinusoidal projection (SIN) and delivered in HDF data format. In the present work, the recent MODIS product level V005 was used. LST is observed by the two MODIS sensors four times per day $(01: 30,10: 30,13: 30,22: 30$, approx. local solar time) originally at $1000 \mathrm{~m}$ pixel resolution. The LST/E product is based on other MODIS data and further auxiliary maps for input, including geolocation, radiance, cloud masking, atmospheric temperature, water vapor, snow, and land cover. Temperatures are provided in Kelvin. For areas with known emissivities in the range $-10{ }^{\circ} \mathrm{C}$ to $50{ }^{\circ} \mathrm{C}$, the MODIS LST algorithm is aimed at reaching a better accuracy than 1 Kelvin with a standard deviation of $+/-0.7$ $\mathrm{K}$ [13]. All known low quality pixels in each LST map are marked in an accompanying quality assessment (QA) layer.
The MODIS LST map reconstruction was executed by performing an automated data download, reprojection to a commonly used map projection system, data format conversion for the GIS import, and a complex procedure to eliminate temperature outliers and to reconstruct the LST datum in areas with no data. For this last procedure, temperature gradient based models were used. Input data points were subsequently interpolated with volumetric splines to obtain complete LST maps. In contrast to other approaches like [10] where the 8-day composited LST data (MOD11A2) were used, this study is based on daily data (MOD11A1 and MYD11A1).

Winkler index is defined as the sum of the mean daily air temperature above $10^{\circ} \mathrm{C}\left(50^{\circ} \mathrm{F}\right)$ calculated from $1^{\text {st }}$ April to $31^{\text {st }}$ October [1] (Eq. 1) in the Northern hemisphere.

Winkler Index $(W I)=\sum_{i=A p r i l, 1}^{\text {October }, 31} \max \left[\left(T_{\text {avg }}\right)_{i}-10 ; 0\right] E q .1$

where, $T_{a v g}$ is the mean daily air temperature, $\max$ is the function which returns the largest value between sets of data $\left(\mathrm{T}_{\mathrm{avg}}-10\right.$ and 0$)$. If the mean daily air temperature is lower than $10^{\circ} \mathrm{C}$, than the max function returns 0 .

Since only four MODIS-LST maps were available for each day, the daily mean value for each pixel was approximated with the average of maximum and minimum values in the set of 4 LST data.

\section{MODEL VALIDATION}

Annual maps of Winkler Index derived from MODIS-LST have been validated by air temperature data from 86 weather stations, registered at $2 \mathrm{~m}$ height above ground (Fig. 1).

Model validation was performed by plotting observed versus predicted values according to [9].

The spatial variability of absolute residuals in the $\mathrm{x}, \mathrm{y}$ and $\mathrm{z}$ was then assessed by a LOESS function using the car package into $\mathrm{R}$ ( $\mathrm{R}$ Development Team, 2011) software (scatterplot.matrix function).

Fig. 1. Average Winkler Index map over 8 years (20032010) derived from processed MODIS-LST data. Circles indicate the weather stations used for validation and their colours represent the error of the estimation (IW MODIS $_{-}$ IW $W_{\mathrm{WS}}$ ) 


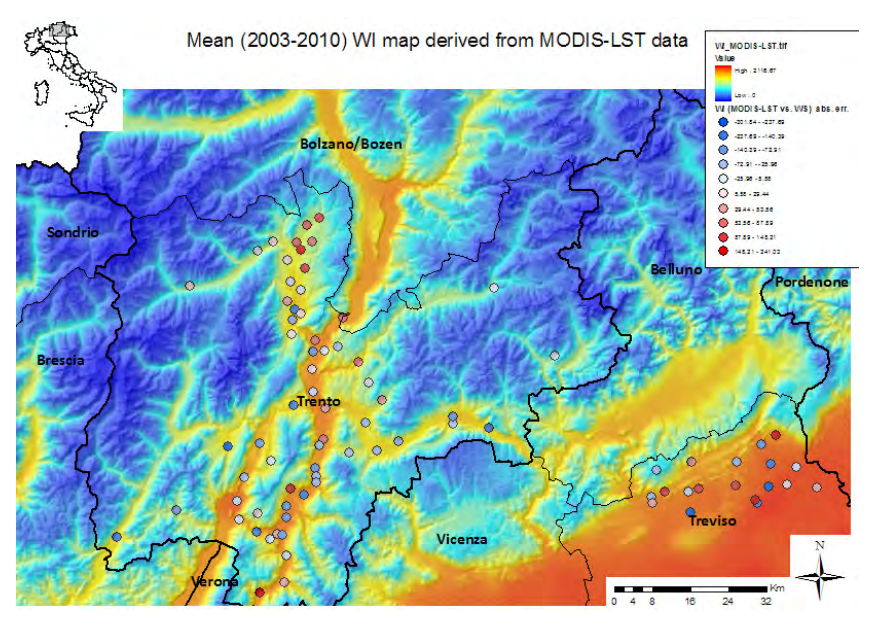

\section{RESULTS AND DISCUSSION}

The results of the validation analysis show a linear high significant linear regression between MODIS-LST and air temperature data. Slopes coefficients varies from 0.936 in 2008 to 1.053 in 2005 (Fig. 2). The average value over 8 years is 0.995 . The determination coefficients (Pearson $\mathrm{R}^{2}$ ) ranges between 0.851 in 2006 and 0.936 in 2008; the mean $\mathrm{R}^{2}$ is 0.905 .

Fig. 2. The scatter plot represent the relation (red line) between mean observed versus predicted values, with a slope of 0.96 deviating from the perfect prediction slope only once higher Winkler values were reached.

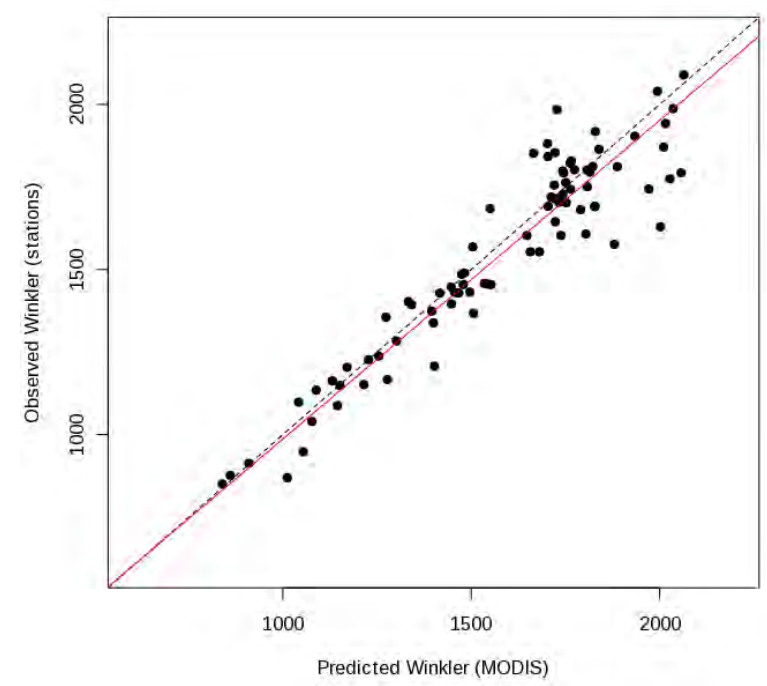

Scatter-matrices related to the variability of absolute residuals in the $\mathrm{x}, \mathrm{y}$ and $\mathrm{z}$ (Fig. 3) showed a positive but noisy trend between absolute residuals and longitude and a negative relationship with both latitude and elevation (apart for an outlier value in the latter case).
Fig. 3. Graphical analysis of the residual.

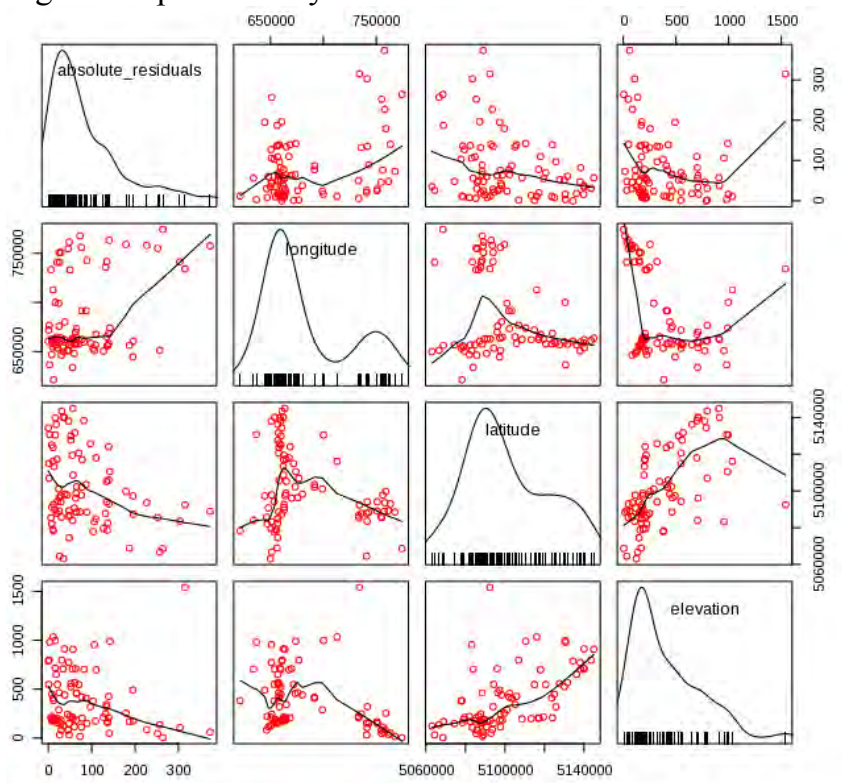

Based on these results the average map over 8 years has been used to classify the region using the Winkler ranges (Fig. 4). Most of the mountain areas results to cool (non suitable; WI < 1371) for viticulture. Moderate cool climate areas (Region II, blue) are suitable for early grape varieties (i.e. Pinot noir, Chardonnay, Riesling, Mueller Thurgau), Region III (green) is warmer and allow the ripening of red varieties (Merlot, Cabernet Sauvignon). Region IV (orange) is hot and suitable for late ripening red grape varieties such as Cabernet franc, Syrah.

Fig. 4. Land suitability for viticulture based on Winkler Index classification.

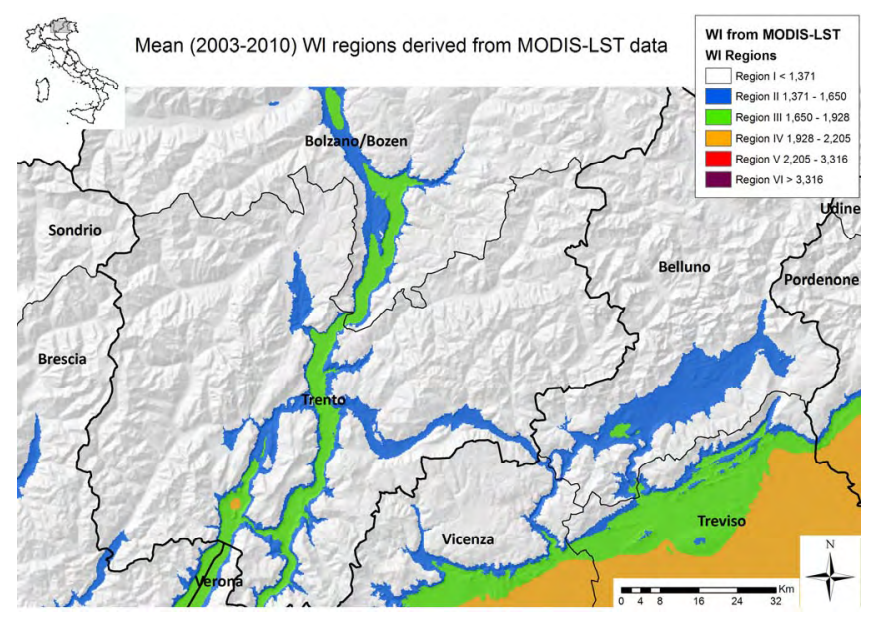




\section{CONCLUSION}

While remote sensing data are currently more easily available (especially from data providers in the USA), the important preparation steps are still very time consuming. Nonetheless, as shown here, the processing can be implemented as an almost entirely automated procedure which can be run on even large grid or cluster infrastructures for parallel computing. These results show that reconstructed daily LST time series are a valid data set which can substitute meteorological temperature observations for the calculation of Winkler Index maps and to assess land suitability for viticulture, especially when the distribution of the stations is irregular or sparse.

\section{REFERENCES}

[1] M.A. Amerine and A.T. Winkler, "Composition and quality of musts and wines of California grapes", Hilgardia 15, Agricultural Experiment Station Berkeley, California, pp. 493-675, 1944.

[2] Q.K. Hassan, C.P.-A. Bourque, F.R. Meng, and W. Richards, "Spatial mapping of growing degree days: an application of MODIS-based surface temperatures and Enhanced Vegetation Index", J Appl Remote Sens 1(1) 013511, Wei Gao - Colorado State University, pp. 1-12, 2007.

[3] W.M. Jolly, R. Nemani and S.W. Running, "A generalized, bioclimatic index to predict foliar phenology in response to climate", Glob. Change Biol. 11, WileyBlackwell, Hoboken New Jersey, pp. 619-632, 2005.

[4] G.V. Jones, A.A. Duff, A. Hall and J. Myers, "Spatial Analysis of Climate in Winegrape Growing Regions in the Western United States", Am J Enol Vitic 61(3), American Society for Enology and Viticulture, Davis California, pp. 313-326, 2010.

[5] C.O. Justice, J.R.G. Townshend, E.F. Vermote, E. Masuoka, R.E. Wolfe, N. Saleous, D.P. Roy, and J.T. Morisette, "An overview of MODIS Land data processing and product status". Remote Sens Environ 83, Elsevier, Amsterdam The Netherlands, pp. 3-15, 2002.

[6] I. Kasprzyk, "Forecasting the start of Quercus pollen season using several methods - the evaluation of their efficiency", Int J Biometeorol 53, Springer, Basel Switzerland, pp. 345-353, 2009.

[7] M. Neteler, "Estimating daily Land Surface Temperatures in mountainous environments by reconstructed MODIS LST data", Remote Sens 2(1), MDPI AG, Basel Switzerland, pp. 333-351, 2010.

[8] L. Pasotti, M. Maroli, S. Giannetto, and E. Brianti. "Agrometeorology and models for the parasite cycle forecast." Parassitologia 48(1-2), Società italiana di parassitologia, Roma Italy, pp. 81-83, 2006.

[9] G. Piñeiro, S. Perelman, J.P. Guerschman, and J.M. Paruelo, "How to evaluate models: Observed vs. predicted or predicted vs. observed?", Ecol Model 216 (3-4), pp. 316$322,2008$.

[10] J.P. Scharlemann, D. Benz, S.I. Hay, B.V. Purse, A.J. Tatem, G.R. Wint, and D.J. Rogers, "Global Data for Ecology and Epidemiology: A Novel Algorithm for Temporal Fourier Processing MODIS Data", PLoS ONE 3(1): e1408, Public Library of Science (PLoS), San Francisco California, pp. 1-13, 2008.

[11] A.J. Tatem, S.J. Goetz, and S.I. Hay, "Terra and Aqua: new data for epidemiology and public health", Int J Appl Earth Obs 6, Elsevier, Amsterdam The Netherlands, pp. 3346, 2004.

[12] N. Valentini, G. Me, R. Ferrero and F. Spanna. "Use of bioclimatic indexes to characterize phenological phases of apple varieties in Northern Italy", Int J Biometeorol 45, Springer, Basel Switzerland, pp. 191-195, 2001.

[13] Z. Wan, Y. Zhang, Q. Zhang, Z.L. Li, "Quality assessment and validation of the MODIS global land surface temperature", Int J Remote Sens, Remote Sensing and Photogrammetry Society, Nottingham United Kingdom, pp. 261-274, 2004. 